\title{
Antonio Candido y David Viñas: LA CŔ́TICA LITERARIA Y EL CIERRE DEL PASADO HISTÓRICO
}

GonZalo Aguliar

Universidad de Buenos Aires - Conicet

\section{Resumo}

Neste texto se ensaia uma comparação entre dois livros fundadores da crítica literária moderna latino-americana: Formação da literatura brasileira de Antonio Candido e Literatura argentina y realidad política do argentino David Viñas. A partir de uma análise de seus postulados, investigam-se as diferenças e o porquê desta fundação tão diversa no Brasil e na Argentina.

Abstract

This text compares two seminal books in modern Latin American literary criticism: Antonio Candido's Formação da literatura brasileira and Argentine critic David Viñas' Literatura argentina y realidad política. Through a comparative analysis of their basic postulates, differences are assessed and the reasons for the notable dissimilarities between the Brazilian and the Argentine foundational books are explored.
Palavras-chave

Dialética;

Literatura

nacional;

Historicidade
Keywords

Dialectic;

National

literature;

Historicism 
los estudios comparativos de crítica latinoamericana, Antonio Candido siempre ha sido puesto en relación - indefectiblemente - con Ángel Rama. Las afinidades que existen entre ambos escritores, el hecho de que se hayan conocido personalmente y de que Rama haya reconocido la importancia de Formação da literatura brasileira en su propia obra son algunos de los factores que explican el lugar privilegiado que se le ha otorgado a esta comparación. Sin embargo, la idea de afinidad que rige el cotejo entre Candido y Rama no deja de tener sus efectos negativos: por un lado, desemboca casi inexorablemente en un esquema de "vidas paralelas" que suprime la singularidad de cada obra y que lleva a la crítica a subrayar, encontrar y hasta inventar coincidencias y semejanzas. ${ }^{1}$ Por otro, el cotejo entre ambos tiende a obturar otras relaciones menos pendientes de las afinidades y de los contactos personales. Con el objetivo de ampliar el juego comparativo y de eludir la tentación identitaria de vincular solamente aquello que supuestamente se asemeja, propongo en este trabajo confrontar la Formação da literatura brasileira de Antonio Candido con un libro que fue editado pocos años después y que forma parte del canon de la crítica moderna argentina: en refiero a Literatura argentina y realidad política de David Viñas, cuya primera edición es de $1964 .^{2}$

La historiografía posterior ha señalado un rasgo que caracteriza el papel que ambos escritores han desempeñado en sus respectivos países: según una idea que tuvo gran aceptación, Antonio Candido y David Viñas fueron los fundado-

\footnotetext{
${ }^{1}$ Una excepción la configura el documentado libro de Pablo Rocca que confronta las obras de Ángel Rama con las de Antonio Candido y Emir Rodríguez Monegal: Ángel Rama, Emir Rodríguez Monegal y el Brasil: Dos caras de un proyecto latinoamericano. Montevideo, Ediciones de la Banda Oriental, 2006.

${ }^{2}$ David Viñas nació en la Argentina en 1927 y es novelista, ensayista y dramaturgo. Fue integrante y miembro fundador de la revista Contorno que modernizó la crítica literaria argentina (en esta revista participaron, entre otros, Ismael Viñas, Noé Jitrik, León Rozitchner, Ramón Alcalde, Adelaida Gigli, Oscar Masotta y Juan José Sebreli). Esta generación fue denominada por la crítica "denuncialista" por la
} 
res de la crítica moderna. Pero en tanto 'fundadores' ellos son muy diferentes entre sí no solo por la fisonomía que le otorgaron al acto fundacional, sino también por los efectos que sus obras tuvieron en la crítica que les sucedió.

\section{Contextos de pensamiento}

Literatura argentina y realidad política consta, en su primera versión, de cuatro partes: "Constantes con variaciones", "El liberalismo: negatividad y programa", "El apogeo de la oligarquía" y "La crisis de la ciudad liberal". Mientras las tres últimas partes trazan el consabido esquema emergencia, apogeo y decadencia, la primera ("Constantes con variaciones") trabaja con dos tópicos que si bien se enuncian durante el Romanticismo, se mantienen como invariables de la cultura argentina siendo detectables aún en los escritores contemporáneos. El primer tópico ya había sido enunciado en "Los dos ojos del romanticismo", artículo publicado en Contorno. Hay en el Romanticismo argentino, según la opinión de Viñas, una suerte de mirada estrábica con un ojo que mira hacia la patria y otro que mira hacia Europa. Viñas desarrolla este argumento en relación con los primeros viajeros de la Independencia hasta llegar al viaje de izquierda de los años cincuenta en la figura de León Rozitchner (1924), un compañero de generación del propio Viñas, cuyo viaje tendría un sentido crítico y desmitificador tanto con el embelesamiento por Europa de las generaciones anteriores como con el carácter conservador y elitista de esa mirada. Rozitchner es el viajero de izquierda que, en diálogo con Sartre y Merleau-Ponty, puede superar dialécticamente la tradicional postura de servilismo y sumisión de la periferia hacia las metrópolis europeas, principalmente París. El otro tópico es el de los "criados" y "niños favoritos", algo bastante semejante a la figura del "agregado" que trabaja Roberto Schwarz en Machado de Assis, que Viñas extiende desde la novela romántica Amalia de José Mármol (1818-1871) pasando por un integrante de la generación del 80 - Lucio V. López (1848-1893) y su novela La gran aldea - hasta llegar a Beatriz Guido (1924-1988). Ambos tópicos - deseo e impotencia por ser como Europa y necesidad del criado para confirmar la condición de amo del escritor - llevan a Viñas a una impugnación en conjunto de una tradición a la que denomina, alternativamente, "proyecto liberal" o "oligárquico". El saldo general es claramente negativo y la clase dominante aparece construyendo una literatura subordinada a un proyecto político que, a medida que pasa el tiempo, deja ver su carácter antidemocrático, antipopular y dependiente del capitalismo metropolitano. Si el libro, pese a su negatividad, está lejos del panfleto o de la mera denuncia, es por el efecto encantatorio que produce la escritura de Viñas que elude el anquilosamiento de la escritura aca-

desmitificación que hizo de la tradición, la historia nacional y los escritores consagrados. Algunas de las novelas más importantes de Viñas son Cayó sobre su rostro (1955), Un Dios cotidiano (1957), Los dueños de la tierra (1958), Dar la cara (1962), Cuerpo a cuerpo (1979) y Prontuario (1993). En el campo de la crítica, además de Literatura argentina y realidad politica, hay que mencionar Indios, ejército y fronteras de 1982 . 
démica y utiliza recursos retóricos sorprendentes, con un léxico provocativo y una capacidad para acuñar conceptos y fórmulas eficaces que, con el tiempo, se convirtieron en lugares comunes de la crítica. Algo de las conversaciones y discusiones alrededor de la mesa de café - tan típicos de la intelectualidad porteña - se traspasa al ritmo andante del libro que todavía hoy sigue siendo cautivante. ${ }^{3}$ Así, a propósito de las Causeries de Lucio V. Mansilla, escritor de la generación del ochenta, Viñas escribe:

\begin{abstract}
El gentleman causeur exhibe su intimidad, se declara desgraciado, pero la mostración de su miseria se da hacia un auditorio privilegiado y referida a un escenario de excepción: entre el causeur y su auditorio se ha tendido un vaso comunicante y como ese conducto es recorrido solo por un fluido azul hasta las propias miserias se convierten en valores. Es el precio que se paga por ser un sólido y elegante servidor de su clase: el spleen es una enfermedad de señores y tomar a la literatura como antídoto contra el aburrimiento el dato principal de un síndrome de clase. ${ }^{4}$
\end{abstract}

Una de las peculiaridades del planteo de Viñas es que a la vez que ha ofrecido una grilla de lectura de la literatura argentina siglo XIX, sus extensiones hacia el siglo pasado son más esporádicas y sólo raramente poseen la eficacia de las lecturas que hace de los textos decimonónicos. Aunque la primera versión en consonancia con el argumento de denunciar la tradición liberal - termina en 1910, año del Centenario de la Revolución de Mayo, en sucesivas reescrituras y reediciones, Viñas incorporó a escritores contemporáneos como Julio Cortázar, Jorge Luis Borges y Rodolfo Walsh. De todos modos, buena parte de los grandes escritores del siglo XX (Borges, Macedonio Fernández, Oliverio Girondo, Alejandra Pizarnik o Manuel Puig, por nombrar sólo algunos) quedan afuera de sus planteos. Esto se debe a que Viñas es particularmente sagaz para leer los modos de una literatura que está al servicio de un proyecto político pero que no tiene una respuesta a los procesos modernos de autonomización que comienzan, por lo menos, a fines del siglo XIX con el Modernismo rubendariano sino antes. Los términos del título (literatura, argentina, realidad, política) son intercambiables, permutables y se condicionan mutuamente, aunque el factor político termina siendo el más determinante. La denuncia se centra en el nexo entre literatura y política y cuando ese nexo se vuelve más complejo, la denuncia pierde su principal anclaje.

Otra razón explicativa de lo decimonónico de su perspectiva lo proporciona Carlos Altamirano quien, en la presentación del libro Historia de los intelectuales en América Latina, definió a los integrantes de Contorno como "historiadores de las elites". Viñas organiza el libro según los ciclos de la elite y a la vez la historiza: los textos que produjeron dejan de ser canónicos o sagrados y son leí-

${ }^{3}$ Tomo esta observación de una intervención de Graciela Silvestri en el Seminario de Historia de las ideas, los intelectuales y la cultura "Oscar Terán", realizado en el Instituto Ravignani de la Universidad de Buenos Aires, en el que se le dedicó una reunión a David Viñas.

${ }^{4}$ David Viñas. Literatura argentina y realidad política. Buenos Aires, CEAL, 1982, p.178 (reproduce la versión de 1964). 
dos en contrapunto con el proyecto autoritario de la elite liberal (aunque sería más exacto decir conservadora, malentendido que se continúa hasta el día de hoy en la terminología política argentina). Mi hipótesis es que la posibilidad de hacer una historia de las elites y de su literatura sólo es posible después de la profunda modernización que se vive en los años cincuenta, cuando una nueva camada social comienza a ocupar posiciones claves en la producción cultural (porque en las vanguardias, más allá de su radicalismo, los protagonistas seguían proviniendo básicamente de las elites). Fue esa encrucijada particular de los años cincuenta - que en la Argentina se denominó "desarrollismo"- la que permitió a estos jóvenes - todos ellos provenientes de la Universidad de Buenos Aires - cierta distancia para observar la historia de un grupo que hasta no hace muchos años había controlado los resortes claves de poder. En el caso argentino, esta perspectiva estuvo marcada por la existencia de los primeros gobiernos peronistas (1945-1955) que no lograron hacer un recambio cultural de importancia a la vez que obturaron la posibilidad de que los jóvenes grupos de izquierda, desencantados con el Partido Comunista, tuvieran una relación menos conflictiva con la cultura popular, incluida dentro de la órbita del peronismo. Críticos con el peronismo, los integrantes de Contorno se alejaron también de los intelectuales tradicionales, ligados a la elite y a las posturas liberales. Esto les permitió abandonar la circularidad de las posiciones disponibles para observar con mayor distancia, gracias al intervalo producido por la modernización y la situación política, el papel que había desempeñado en la historia argentina la elite dirigente, comprometida en bloque con el antiperonsimo.

El enunciado que abre la primera versión de Literatura argentina y realidad política, entonces, debe leerse como la descripción del proyecto de una elite a la que se considera en estado terminal: "La literatura argentina es la historia de la voluntad nacional". La ironía es evidente porque es esta "voluntad nacional" la que será puesta en cuestión. Erigida como objeto de la crítica y sujeto de la historia, la voluntad nacional que se organiza durante los años de la Independencia y del Romanticismo, puede ser vista a mediados del siglo XX como agotada y fracasada. Con distintos matices, en las sucesivas reescrituras del libro, Viñas intentará acechar y atrapar esta "voluntad nacional" con una serie de tensiones y contradicciones que no podían escapar al crítico: porque si la "voluntad nacional" ya cumplió su ciclo, ¿por qué mantener la afirmación de su existencia en presente? En la edición de 1971, titulada De Sarmiento a Cortázar (Literatura argentina y realidad politica), se lee: "la literatura argentina es la historia de la voluntad nacional encarnada en una clase con sus textos, proyectos, modelos y procedimientos", donde el término clase acentúa la perspectiva marxista del autor que ya articulaba casi todos los argumentos de la primera versión. Finalmente, en la versión de 2005, la frase inaugural aparece de la siguiente manera: "La literatura argentina se va justificando como la historia de un proyecto nacional". A renglón seguido, se habla de los "momentos culminantes" como aquellos que van puntuando la periodización. El "proyecto nacional" (sintag- 
ma, por otro lado, muy utilizado por el peronismo) se expresa con el gerundio "justificando", como abriendo la posibilidad de diferentres reencarnaciones en diferentes actores sociales (movimiento que le permite extender hasta el presente el periodo abarcado). Es como si el gran drama - otro término viñesco - de la literatura argentina fuera su imposibilidad de escapar de su posición dominante y señorial en el entramado social aunque para eso haya que dejar en un segundo plano la dinámica de la autonomización literaria.

El inicio de Literatura argentina y realidad política puede evocarle al lector reminiscencias del primer capítulo de Formação da literatura brasileira:

\footnotetext{
"Esses críticos conceberam a literatura do Brasil como expressão da realidade local e, ao mesmo tempo, elemento positivo na construção nacional. Achei interessante estudar o sentido e a validade histórica dessa velha concepção cheia de equívocos, que forma o ponto de partida de toda a nossa crítica, revendo-a na perspectiva atual. Sob este aspecto, poder-se-ia dizer que o presente livro constitui (adaptando o título do conhecido estudo de Benda [Esquisse d'une histoire des Français dans leur volonté d'être une nation]) uma história dos brasileiros no seu desejo de ter uma literatura". ${ }^{5}$
}

El reconocimiento de una voluntad o de un deseo del otro es, en ambos casos, fundamental para historiar una literatura, situación que no impide sino que más bien requiere un distanciamiento. Este distanciamiento lo proporciona el método dialéctico con la diferencia de que en Viñas la negación es exterior mientras en Candido se complementa con el momento de identificación que no se abandona a lo largo del libro. Considero que las diferentes posturas en relación con esa voluntad explican las diferencias de los recorridos y de los argumentos de uno y de otro. En Viñas se produce una situación traumática que impide el cierre de esa tradición (la exterioridad no admite negociaciones) mientras en Candido la formación cumple su ciclo a fines del siglo XIX y en la figura de Machado de Assis. Esto puede observarse, por ejemplo, en el hecho de que Candido sólo haya dado por concluido su libro una vez editado y sólo haya hecho pequeñas correciones y un prefacio en 1962. Literatura argentina y realidad politica, en cambio, es un libro abierto, sometido a diferentes versiones y reescrituras: no hay punto final porque el proceso identificatorio de Viñas con el pasado literario argentino es mucho más traumático. Se trata de un ciclo que no puede cerrarse y que no deja de abrirse con el devenir histórico: la idea de que la literatura argentina es fundada con una violación - la que se lee en la novela Amalia de José Mármol - retorna con la dictadura militar y el secuestro y la posterior desaparición del escritor Rodolfo Walsh, más de cien años después. Las "constantes" desbaratan los procesos de formación (de ahí la importancia del gerundio en la última versión).

A diferencia de Antonio Candido que en las diferentes reediciones de su libro hizo pequeñas correcciones y eventualmente agregó "prefacios", las diver-

\footnotetext{
${ }^{5}$ Antonio Candido. Formação da literatura brasileira 1. São Paulo: Martins, 1975, p. 25.
} 
sas modificaciones del libro de David Viñas están vinculadas con los cambios políticos. El carácter de los epígrafes deja ver estos vaivenes: del Robert Escarpit en la primera edición, pasando por Mao Tse-Tung en la edición de 1971, hasta Terry Eagleton en 2005. En las reescrituras, Viñas agregó páginas, mezcló capítulos, reorganizó el conjunto, modificó los índices. En 1971, publicó De Sarmiento a Cortázar (Literatura argentina y realidad política) con dos nuevos capítulos y como parte de un programa más completo de historia de la literatura argentina que iría a constar - según el proyecto presentado en el prólogo - de los siguientes volúmenes: "De Sarmiento a Cortázar", "El liberalismo: negatividad y programa", "El apogeo de la oligarquía", "La crisis de la ciudad liberal", "Señores, bohemios y anarquistas", "Yrigoyenismo, clases medias y vanguardia", "La década infame", "El peronismo" y "Del 55 al 70". Los títulos corresponden más a una periodización hecha según la serie política que la literaria (Yrigoyen fue el presidente en dos periodos de 1916 a 1922 y de 1928 a 1930, "55" se refiere a la fecha en la que fue derrocado el gobierno de Perón, etc.). Finalmente, estos libros proyectados y nunca escritos pasaron a formar parte de una Historia social de la literatura argentina que está siendo editada actualmente. ${ }^{6}$ En 2005, Viñas volvió a reeditar Literatura argentina y realidad política cambiándole el título (Literatura argentina y política) e introduciendo algunos cambios. Es como si no pudiera poner punto final, como si la tensión entre la propuesta de una clave para leer la literatura decimonónica y la necesidad de intervenir en el presente no pudiera ser resuelta, hecho que - creo yo - no debería asignarse a las sucesivas frustraciones de la política argentina sino a la resistencia de Viñas a considerar el ciclo de la "ciudad liberal" concluido y agotado. Oliverio Girondo, Victoria Ocampo, Jorge Luis Borges, Bioy Casares o Manuel Mujica Láinez son miembros de la elite pero la autonomización literaria que construyen o por la que deben pasar funda una situación absolutamente nueva y discontinua en relación con los escritores-políticos o "gentleman", como los llama Viñas, del siglo XIX.

El movimiento de Candido se asemeja metódicamente al de Viñas pero uno de sus aportes centrales no está en extender interminable y traumática el proceso de formación sino de introducir en él un elemento al que considera fundacional (el movimiento arcádico) y que se encuentra ya concluido (es decir, reabre el pasado en función del presente y no el presente en función del pasado). En términos metodológicos, entonces, hay un rechazo a la crítica impresionista y se plantea la necesidad de un acercamiento sistemático a la literatura que considere sociológicamente la importancia de la obra, la formación del público y la figura del autor (sin abandonar los penetrantes close readings aplicados a los textos de los autores estudiados). Con esos presupuestos, Candido recupera al

\footnotetext{
${ }^{6}$ Son volúmenes colectivos dirigidos por críticos elegidos por Viñas, quien es el director general de la colección. Algunos títulos son "4 de junio y peronismo clásico (1943-1945-1955)", "Neoperonismo y modernidad (1966-1976)" e "Indios, montoneros, paraguayos (1853-1861-1879)", llegando a editarse hasta el momento sólo dos títulos: "Yrigoyen, entre Borges y Arlt (1916-1930)".
} 
movimiento arcádico como una etapa de la formación a la que después se agregaría la del Romanticismo, haciendo una transformación clave en lo que denomina, en el prefacio a la segunda edición de 1962, "vida nacional". ${ }^{7}$ Reivindica, de ese modo, en momentos en que la modernización está transformando vertiginosamente a la nación, un movimiento - el arcádico - que había sido visto por la crítica como alienado y espurio, y propone, por el contrario, que "fue admirablemente ajustado a la constitución de nuestra literatura" y que contribuyó a una vida nacional abierta y dinámica. Parece evidente que lo que le interesa reivindicar a Candido es el pasado iluminista y un estilo, el neoclásico, con el fin de postular una modernidad más universal y racional y menos implicada en la ideología nacionalista e historicista del Romanticismo.

No escapó a algunos lectores, como Haroldo de Campos, la organicidad y el esquema evolutivo en el que estaba implicado el proyecto de Candido, pero también puede verse esta organicidad como una necesidad de reafirmar tanto un pasado relativamente autónomo como un sistema que se configura sobre la base de los esfuerzos de publicistas y letrados.

A diferencia del libro de Viñas, A formação es un libro cerrado con un trazado que no responde al esquema emergencia, apogeo, caída sino que, en sus "momentos decisivos", avanza hacia la conformación y a la estabilización de una literatura. En todo caso, Candido ha revisado (es decir, reabierto) su libro en dos ensayos de fines de los sesenta, "Literatura y subdesarrollo" y "Dialética da malandragem", que se detienen sobre aquellos objetos que son opacos para las "racionalizaciones ideológicas reinantes" de la modernización cosmopolita y del moralismo decimonónico de la norma burguesa. En ambos, Candido cuestiona las construcciones que, desde una perspectiva evolucionista, se habían hecho de la literatura: en el primero, sosteniendo la persistencia del regionalismo en la literatura latinoamericana; en el segundo, recuperando una tradición satírica que estaba excluida de la formación de la literatura brasileña que había descrito en su libro. Más que reabrir el libro, investiga aquello que - a causa de su identificación con "el deseo de tener una literatura"- había sido excluido o reprimido.

\section{La dialéctica}

Tanto a Viñas como a Candido, la dialéctica como figura del pensamiento les sirvió para aventurarse en la tradición con la distancia crítica que provee la negación. Es necesario tener en cuenta que esas tradiciones - sobre todo en el caso argentino - todavía no habían sido recolocadas por la crítica literaria en tanto disciplina (es decir, considerando la singularidad de la operación literaria). Sin duda, las vanguardias habían hecho un trabajo fundamental de antagonismo y distanciamiento paródico y los años treinta habían puesto de relieve la necesidad de recomponer o de trazar lazos con la tradición, pero lo que su-

\footnotetext{
${ }^{7}$ Antonio Candido. Formação da literatura brasileira 1, op.cit., p.18.
} 
cede con Formação y literatura argentina y realidad política es algo radicalmente nuevo: la posibilidad de cerrar un ciclo del pasado, de acercarse a él de un modo dialéctico (mediante la empatía y la negación), de reflexionar con el instrumental de la crítica literaria moderna y de repensar las escenas de fundación de la literatura nacional. Hay que imaginarse a ambos críticos caminando por sus ciudades (San Pablo y Buenos Aires), urbes ya estabilizadas pero a la vez en plena mutación, con tradiciones propias y que encaran la modernización vertiginosa de los años cincuenta. Desde la opulencia de las calles paulistas o porteñas que reorganizan el territorio nacional, el pasado nacional aparecía como algo que, en tanto había sido dejado atrás, debía ser descifrado. El salto modernizador no era solamente hacia el futuro sino que también - y aquí también la dialéctica gobierna - realizaba desplazamientos hacia atrás y hacia adelante, preservando algo de aquello que negaba como resultado de los movimientos del pensamiento.

Sin embargo, es en la dialéctica misma en donde los métodos de Candido y Viñas divergen y se vuelven profundamente diferentes entre sí. Para Candido, el momento de identificación es necesario y establece el tono comprensivo - y por momentos lleno de afectividad - que atraviesa todo el libro. El deseo de tener una literatura es compartido por el propio crítico aunque eso, por supuesto, no lo exime de advertir que se trata de una "velha concepção cheia de equívocos". Esta constatación no impide que la relación entre dialéctica y modernización sea, en Candido, de ampliación, de incorporación y, más aún, de estabilización entre los diferentes componentes. La razón de esta plasticidad dialéctica radica en que Candido no discute si la literatura brasileña ya está formada o no, sino el método con el que evaluamos ese hecho (la deuda de Candido con otros historiadores de la literatura, como Sílvio Romero, es mayor la que Viñas tiene con Ricardo Rojas, el primer historiador de la literatura argentina).

El momento afirmativo en Viñas, en cambio, excluye la identificación: la literatura argentina está fundada sobre una violación y ese trauma no puede ser apaciguado por el pensamiento crítico. Más bien, la violación continúa como una constante y eso hace que Literatura argentina y realidad política no sólo no pueda concluirse sino que exija ser reescrito, reabierto y reactualizado hasta el día de hoy. Los "momentos" en Candido son decisivos, es decir, avanzan en función del concepto progresivo y acumulativo de la formación. En Viñas son culminantes, son la manifestación de un origen que funda una realidad política traumática que todavía no se ha clausurado. La afirmación y la negatividad dialécticas se hacen, ambas, desde una exterioridad que proporciona - en el planteo de Viñas - la única mirada crítica posible. La gestualidad viñesca es, por supuesto, más atronadora y rebelde que el estilo discreto y equilibrado de Candido, pero los efectos de su discurso son mucho más paralizantes.

El hecho fundamental que hace a ambos libros comparables es, entonces, la presencia del método dialéctico - aunque sus usos sean absolutamente divergentes - y la necesidad de historizar en el caso de Viñas y rehistorizar en el de 
Candido una tradición en un momento en que la modernización requiere nuevas imágenes del pasado. Por eso, en ambos, la historia no es un objeto (ambos eluden el término en sus títulos) sino una exigencia general del pensamiento crítico. Una historicidad, un sentido histórico, para leer el presente en las constelaciones de las literaturas nacionales. 